\title{
En el país de todas las muertes El Salvador, políticas de seguridad y representaciones de los asesinatos
}

\author{
In the country of all deaths. El Salvador, security policies \\ and representations of the murders
}

\section{RESUMEN}

El Salvador es uno de los países con la tasa más alta de homicidios. Pero también con una larga tradición de violencia y autoritarismo. En El Salvador la muerte es, pues, una presencia cotidiana. El presente texto se aproxima y reflexiona dos narrativas referidas a la muerte. Primero, la de los medios de comunicación masiva y la manera cómo construyen una representación gráfica de muertes violentas de pandilleros y policías. Posteriormente, nuestro trabajo analiza la perspectiva del arte, un espacio menos protagónico, más periférico, pero central en la medida en que permite a una sociedad nombrarse por fuera del análisis racional y volver al universo de lo simbólico. Para ello se revisan dos propuestas artísticas significativas, la primera es la exposición Horror Vacui, exposición que da cuenta de distintos artistas plásticos en relación con la sensación de vacío y muerte en el país, y La república de la muerte un ejercicio de una de las artistas salvadoreñas más reconocidas, Mayra Barraza que durante cien días consignó un blog con todas las noticias de muerte que encontró cada día y, a partir de ello, construyó una serie de propuestas estéticas: esculturas, cuadros y otras.

Palabras Clave: Representaciones - El Salvador - Usos políticos de la muerte Medios de comunicación - Arte mortuários - Britannia

\begin{abstract}
El Salvador is one of the countries with the highest homicide rate. However, with a long tradition of violence and authoritarianism, were death is a daily presence. The present text approaches and reflects on two narratives about death. First, that of the mass media and how they construct a graphic representation of violent deaths of gang members and policemen. Later, our work analyzes the perspective of art, a space less protagonist, more peripheral, but central to the extent that it allows a society to be named outside of rational analysis and return to the universe of the symbolic. For this, two significant artistic proposals are reviewed. The first one is the exhibition Horror Vacui, an exhibition that gives an account of different plastic artists in relation to the feeling of emptiness and death in the country. The other is The Republic of Death, an exercise of one of the most recognized Salvadoran artists, Mayra Barraza, who for a hundred days consigned a blog with all the death news that she found every day and that she built from it a series of aesthetic proposals: sculptures, paintings and others.
\end{abstract}

Keywords: Representations - El Salvador - Political uses of the death - Media Art

* Doctora en Filosofía por la Universidad Centroamericana José Simeón Cañas (UCA) de El Salvador. Profesora de la misma universidad. Parte del equipo coordinador del grupo de investigación sobre comunicación política y ciudadanías del Consejo Latinoamericano de Ciencias Sociales (CLACSO) e investigadora del Centro Internacional de Estudios sobre epistemologías de fronteras y economía política de la cultura en Chile. CV: https://uca-sv.academia.edu/AmparoMarroquin

** Maestría en Comunicación por la Universidad Centroamericana José Simeón Cañas (UCA), El Salvador. Profesor e investigador en la Escuela de Comunicación Mónica Herrera, El Salvador. Profesor en la Universidad Centroamericana José Simeón Cañas (UCA), El Salvador. Columnista del periódico El Faro. CV: https://independent.academia.edu/WillianCarballo

*** Investigador independiente. Maestría en Comunicación por la Universidad Centroamericana José Simeón Cañas (UCA), El Salvador. Politólogo. Ha sido director de la iniciativa Debate, Diálogo, y Democracia (3D). Director y co-creador del proyecto Tú Música, Tú Empresa. Fundador y primer director de la revista Ciencia Política. Miembro del Aspen Global Leadership Network (AGLN). Fundador y primer presidente de las Juventudes Socialdemócratas de El Salvador (JSD). CV: http://especiales.elsalvador.com/2015/el-pais-que-viene/perfil-anzora.asp 
Cada uno tiene su pedazo de tiempo y su pedazo de espacio,

su fragmento de vida y su fragmento de muerte.

Pero a veces los pedazos se cambian y alguien vive con la vida de otro

o alguien muere con la muerte de otro.

Casi nadie está hecho tan sólo con lo propio.

Roberto Juarroz (1982)

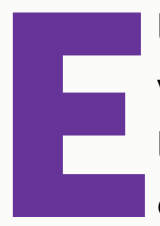

I Salvador es un pequeño país centroamericano situado en una de las regiones más violentas del mundo. En la década de 1980, una prolongada guerra civil llegó a cobrar la vida de más de setenta y cinco mil salvadoreños. Con la firma de los acuerdos de paz entre los bandos enfrentados, un nuevo conflicto social, que se encontraba latente, comenzó a visibilizarse hasta volverse protagónico. Otras violencias y formas de asesinato, cada vez más complejas, que recogían gestos del pasado pero que estaban cargadas con nuevos simbolismos, empezaron a ser contabilizadas. La paz pasó de ser un proyecto a un espejismo en una región que, en distintos momentos, ha sido etiquetada como "la más violenta del mundo" (Bergman, 2015, p. 223).

La antropóloga estadounidense, Elle Moodie, ha señalado que muchos salvadoreños han llegado a referirse a "la paz como algo peor que la guerra" (Moodie, 2017, p. 3), por la cantidad de violencia que se ha vivido y la forma como muchos salvadoreños han experimentado el control de las pandillas, los asesinatos y las políticas discrecionales de distintos gobiernos con decisiones que más bien han agravado la situación.

En el imaginario de la sociedad salvadoreña se instalaron algunas creencias sobre la violencia, se afianzaron otras más y, casi sin saberlo, se fortaleció una narrativa que ya venía sedimentándose en la opinión pública. Esta opinión tiene que ver en parte con el diferente valor de la vida de un ciudadano ejemplar y el de la vida de un pandillero, en marzo de 2016, el presidente de la república, Salvador Sánchez Cerén declaró ante la prensa que "el homicidio está creando esa sensación de que está muriendo la población, pero muchos de esos asesinatos son pandilleros", al decir esto, hizo alusión a un grupo social distinto, los pandilleros no son población, y en sus declaraciones acotó que se refería "[no únicamente a los] 60 mil miembros que, cuando se suman a sus grupos familiares llega a aproximadamente 450 mil personas ly que] no son población afectada". ${ }^{1}$ Esta intervención sintetiza el pensamiento y el sentir de buena parte de la población salvadoreña.

El investigador Adrian Bergman, por ejemplo, cuestiona esas creencias, el muy repetido discurso que la sociedad salvadoreña es ahora más violenta que antes. A través de un cuidadoso trabajo historiográfico se muestra que desde 1900, con la llegada del siglo XX, el país ha tenido siempre tasas muy altas de homicidio: "No obstante las variaciones, una cosa debe quedar clara: la trayectoria de homicidios es muy larga, incluso mucho más de lo que se acostumbra a tomar en cuenta. El nivel de homicidios en El Salvador no se dispara a partir de la guerra ni

1 RAUDA ZABLAH, Nelson. Sánchez Cerén: Aunque algunos digan que estamos en una guerra, no queda otro camino. El Faro. San Salvador, 7/mar/2016. Disponible en: <https://elfaro.net/es/201603/el_salvador/18180/ S\%C3\%A1nchez-Cer\%C3\%A9n-Aunque-algunos-digan-que-estamos-en-una-guerra-no-queda-otro-camino.htm>. Acceso en: 07/01/2018. 
la deportación de migrantes desde Estados Unidos, ni tampoco a partir de los cambios en el escenario de las pandillas" (Bergman, 2015, p. 240). Frente a esta realidad, las narrativas y las representaciones de la muerte sí han cambiado. Las causas y las formas como nos aproximamos a distintos homicidios tienen que ver ahora con nuevas coyunturas: del relato moralizante a la descripción más pulcra; del horror a la indiferencia; del detalle morboso al número gris y masivo, la sociedad salvadoreña construye distintas maneras de nombrar el horror y la muerte en un país en donde todas las muertes son posibles.

\section{Aproximaciones teórico-metodológicas}

No existen estudios académicos en El Salvador propiamente centrados en las representaciones mediáticas, artísticas, estéticas e imaginarios sobre las muertes violentas. Sin embargo, el tema aparece casi siempre como telón de fondo en las investigaciones y artículos académicos que han explorado las narrativas sobre los pandilleros y la violencia en los medios periodísticos. Autores como Marroquín (2007), Vasilachis (2007), Martel (2007), Wolf (2012), Vásquez y Marroquín (2014) y Hernández-Anzora (2017) han contado, aunque con matices, cómo los medios han magnificado la violencia de las pandillas, difundiendo un discurso que demoniza y homogeneiza a sus miembros y crean así la imagen de un villano contra el cual deben luchar aquellos gobernantes que quieran la aprobación del pueblo. La mayoría de estos trabajos llegaron a esas conclusiones tras analizar notas periodísticas protagonizadas por pandilleros, pudiendo ser víctimas o victimarios. O bien tras interpretar el sentido que los lectores dan a esas notas, como lo hicieron Carballo (2015) y Marroquín (2016).

A partir de ese vacío, el presente texto tiene como objetivo reflexionar sobre dos de estas narrativas sobre la muerte: la periodística y la artística. Se trata de dos instituciones que finalmente viven la vida y mueren la muerte de otros, como dice Roberto Juarroz: la de los medios masivos de comunicación, que siguen teniendo un gran nivel de aceptación y de incidencia en las opiniones sobre la inseguridad en el país, la de la representación gráfica, periodística y artística de varias muertes. Como vamos a mostrar, en buena parte de la cobertura mediática que se ha revisado, los pandilleros mueren, aunque las notas estuviesen relatando un enfrentamiento o un procedimiento policial, mientras que los efectivos del Estado son asesinados. Estas conjugaciones en pasiva muestran claramente una diferencia. En el caso de los pandilleros no existe un sujeto. Mueren, como sucede con los desenlaces inevitables de las tragedias. Mueren y no existe ningún culpable. Mueren y la sociedad simplemente es testigo. En el caso de los policías, estos son asesinados por, esta voz implica siempre un agente, alguien que cometió un crimen, alguien que es culpable y debe ser condenado. Posteriormente, mostraremos la perspectiva del arte, un espacio menos protagónico dentro de la sociedad salvadoreña, pero central en la medida en que permite a una sociedad nombrarse por fuera del discurso moderno y volver al universo de lo simbólico.

El presente texto parte de tres investigaciones cualitativas. La primera, una tesis de postgrado elaborada por el investigador Marlon Hernández-Anzora en la que se analizaron 
372 notas, seleccionadas aleatoriamente y que durante 2015 cubrían el tema de las pandillas en distintos medios salvadoreños. Y dos revisiones elaboradas para este trabajo, de seis notas periodísticas seleccionadas intencionadamente como notas modelo, en donde "la muerte" violenta de pandilleros y de ciudadanos "ejemplares" protagoniza la información. Para el apartado de la representación artística, revisitamos la muestra Horror Vacui, una propuesta de siete artistas que producen arte posterior a la guerra, en particular, el área que desde la curaduría se denominó De sangre y zozobra, y que recupera la violencia de la postguerra; y la obra "La república de la muerte" un ejercicio de la artista Mayra Barraza que durante cien días consignó en un blog todas las noticias de muerte que encontró y que construyó a partir de ello una serie de propuestas estéticas.

Para efectos de esta reflexión el concepto teórico central que nos guía es el concepto semiótico de Eliseo Verón que insistirá en que lo fundamental del análisis de los discursos es que estos nos permiten aproximarnos a la construcción social de la realidad. En este caso, una realidad construida en torno a la muerte. Verón introduce el concepto de semantización de la violencia que resulta útil para nuestra reflexión final: "Introducimos el neologismo "semantización" para referirnos al proceso por el cual un hecho «x» ocurrido en la realidad social es incorporado, bajo la forma de significaciones, a los contenidos de un medio de comunicación de masas" (Verón, 1971). Y de manera particular, intentamos revisar también la semantización de la muerte que algunos artistas ofrecen a la sociedad salvadoreña

El análisis se divide en dos momentos. Primero se analiza lo que sucede con el discurso más difundido sobre los asesinatos: el de los medios de comunicación. Desde la opinión pública que circula en periódicos impresos, redes sociales, nuevos medios digitales, televisión y radio se encuentran primero los muertos en aquellos que son héroes, buenos, nobles: los ciudadanos comunes, los campesinos, las familias. En segundo lugar, se encuentran los muertos que merecen morir: los malos del relato. Los pandilleros siempre, sus familias, al final, otro tipo de ciudadanos sin derecho a la ciudadanía plena. Los marginados, los otros para siempre. A partir de ello, este trabajo revisa los usos de los buenos muertos que deben dolernos y los malos muertos que merecen su destino. Finalmente, revisamos, las estéticas, a través de la obra de distintos artistas, la posibilidad de trascendencia en un país en donde el sentido denotativo y literal parece predominar en estas representaciones. Creemos que el uso político de estos discursos es, también, otra forma de ideología que el arte nos permite revisar con ojos críticos.

\section{Los que mueren en los medios de comunicación: de víctimas, héroes y mártires. Nuevo panegírico de la nación de todos los muertos}

Aquí la muerte es un espectáculo. Yo en los ochenta cuando cubría muertos en la calle tenías alrededor a gente mirando, esperando a que vengan a tomar fotos. Si yo te muestro fotos que yo tomé en esos años, la gente está posando. ¡Está el muerto y están posando! Y hoy es lo 
mismo. Hoy hay un muerto y ves a la gente que va con los niños. ${ }^{2}$

El 13 de diciembre de 2017, uno de los sitios digitales de noticias más visitados de El Salvador, La Página, publicó una nota bajo el titular: "Consterna imagen de asesinato de campesino en Cacaopera". El texto iba acompañado de la fotografía que acotaba la afirmación. No mostraba un grupo de ciudadanos alterados, sorprendidos o aterrados. En ella, más bien, el cuerpo de un joven agricultor de 20 años de edad lucía ensangrentado y tendido sobre el suelo polvoriento de uno de los municipios más rurales al oriente del país. Cacaopera, en el departamento de Morazán. La víctima portaba aún su sombrero de paja y calzaba sus botas de caucho. Además, a un lado del cadáver se podía apreciar una botella reutilizada con agua; y al otro, el machete que los campesinos salvadoreños suelen utilizar como instrumento fundamental para sus labores.

Figura 1 - Publicación de La Página

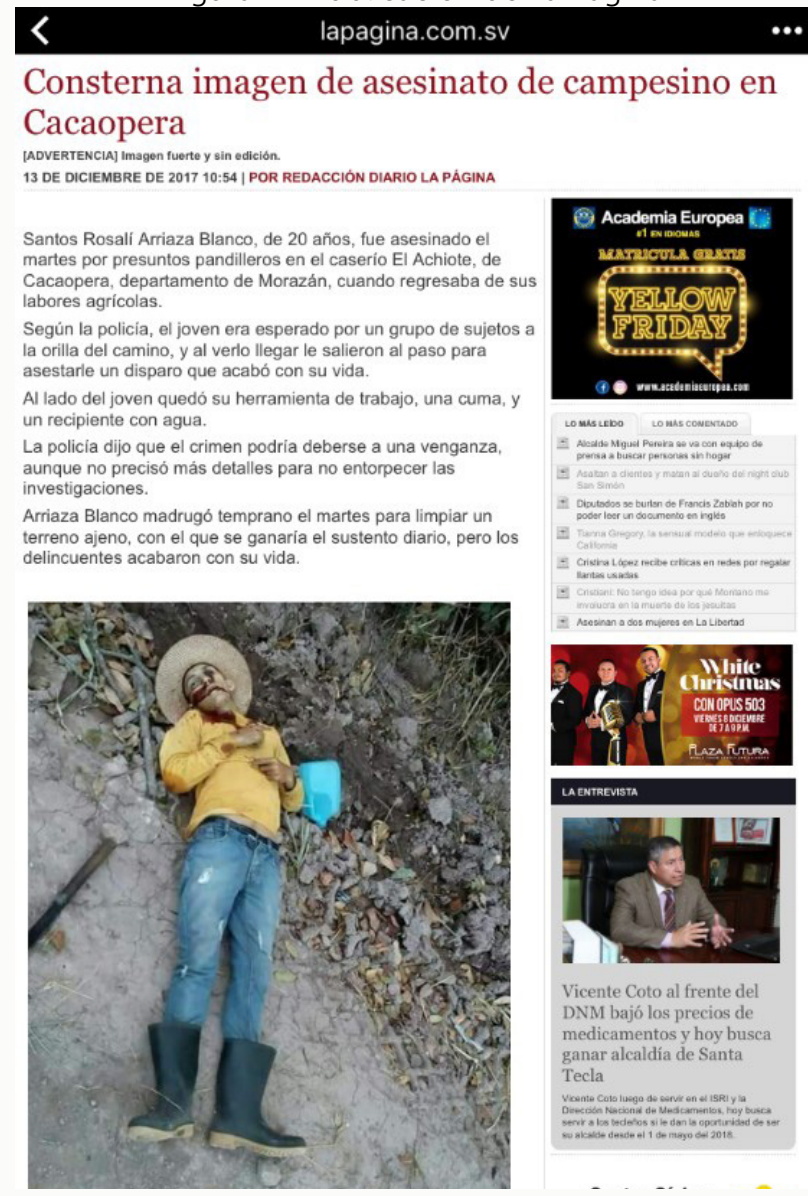

Fuente: Captura de Pantalla de www.lapagina.com.sv (20 de diciembre 2017)

La nota, en coherencia con lo que algunos estudios sobre la calidad del periodismo judicial en la nación centroamericana han revelado (Flores Argueta, 2014), estaba basada solo

2 El Faro. El Salvador, 09/07/2007. 
en una fuente policial y luego carecería de seguimiento periodístico, hasta perderse como una más de las decenas de casos de asesinatos que los medios locales reportan cada semana sin profundizar en ellos. El texto establecía que el joven había sido "asesinado por presuntos pandilleros". Luego, citando a la Policía Nacional Civil (PNC), afirmaba que "el joven era esperado por un grupo de sujetos a la orilla del camino, y al verlo llegar le salieron al paso para asestarle un disparo que acabó con su vida". En resumen: "La policía dijo que el crimen podría deberse a una venganza".

En cambio, en aquellas notas en las que la víctima - según la única fuente consultada, que casi siempre es la Policía o la Fiscalía - no tiene vínculos criminales, la construcción noticiosa va enfocada a dos aspectos: uno, a explotar todos aquellos elementos que hacen parecer a dichas personas como pérdidas reprochables para la sociedad; y dos, a reforzar la idea de que sus atacantes merecen repudio e, incluso, la muerte en venganza por sus acciones. En el caso del campesino, la pieza periodística cierra con que el joven "madrugó temprano el martes para limpiar un terreno ajeno, con el que se ganaría el sustento diario, pero los delincuentes acabaron con su vida". El joven era trabajador; los perpetradores, unos verdugos. El joven representaba una sociedad pacífica, agricultora, idílica. El joven ha sido prácticamente un mártir de una violencia desbordada.

La imagen misma, además, a no ser por el hecho que cubre, parece reflejar una cierta serenidad, la luz ilumina la composición, sin dejar espacios oscuros y el cadáver se presenta ante el espectador en actitud serena. Los colores son cálidos: azul, amarillo, rojo... y parecería un cuadro renacentista trágico, de no ser porque sabemos que no hubo intervención en la composición misma del espacio.

Pero hay también otras notas que son claro ejemplo de este tipo de presentación de la muerte. El también popular diario digital El Blog publicó el 1 de noviembre de 2017 una noticia titulada: "Esta es la linda familia asesinada por pandilleros en Santa Ana". Como en el caso del campesino, la imagen juega un papel fundamental. El texto es acompañado por una fotografía de un padre, la madre y una niña. Se trata de la familia de un agente de la PNC. Él, junto a su esposa, su hija, de 4 años, y un sobrino fueron asesinados por pandilleros en la zona límite de los municipios de El Congo y Coatepeque, en el occidental departamento de Santa Ana, según la misma noticia.

En este caso, la imagen no presenta la escena del crimen, sino que muestra al lector una foto familiar de las víctimas en un momento anterior a su muerte. La imagen es evidentemente conmovedora: es el retrato truncado de un joven miembro de la corporación policial y su familia más cercana, incluyendo una menor de edad con el futuro por delante. Esta foto y el adjetivo "linda" en el titular se mezclan para dejar claro que estas son el tipo de víctimas que duelen perder en la coyuntura de violencia que vive El Salvador. Y en efecto, resulta innegable que la muerte de un policía, de su esposa y de dos niños es repudiable, así como las de los 46 miembros de la PNC que fueron asesinados en 2016.

Este tipo de tratamiento de la imagen de un asesinado no es algo nuevo. También consternaba lo que se miraba en una famosa y premiada foto publicada por el El Diario de Hoy (elsalvador.com en su versión en línea) en 2008. Esa imagen, que se agenció el premio World 
Press Photo y que fue captada por la periodista gráfica, Lissette Lemus, mostraba el cadáver de una madre de familia asesinada con arma de fuego, mientras un grupo de niños abordo de un microbús escolar observaban el cuerpo y un charco de sangre. La foto, que impactó desde el primer momento por su crudeza, se convirtió también en una denuncia de las situaciones que tenían que testificar los menores de edad en el país de todas las muertes. Los rostros de los chicos no aparecen aterrorizados, sino más bien curiosos. Se constata así una realidad que resulta más cotidiana de lo que muchas veces la sociedad salvadoreña quiere aceptar.

Imagen 2 - Foto publicada en El Diario de Hoy, tomada por Lissette Lemus

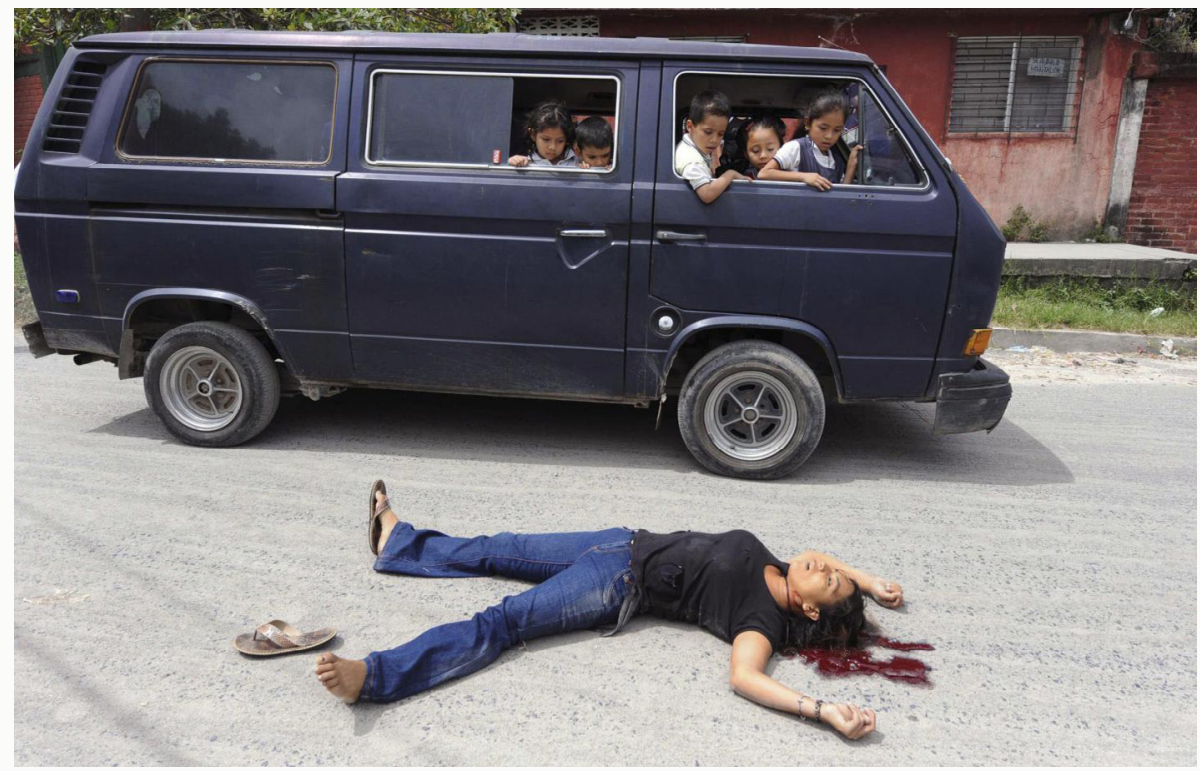

Fuente: El Diario de Hoy. https://www.worldpressphoto.org/people/lissette-lemus (15/10/2017)

Pero nos parece importante destacar en el análisis no solo estas imágenes que conmueven, como es natural, sino, más bien, esas otras muertes publicadas en los medios que en El Salvador parecen incluso legitimarse.

La brevedad e incluso la vaguedad de la información y la utilización de una sola fuente, sin embargo, no evitaba fijar la atención en un detalle no menor del titular: que esta muerte contraria a otras publicadas en ese y otros medios - consterna. ¿Qué hace que consterne? ¿Por qué se lamentan unos asesinatos y otros no? ¿Por qué otros incluso parecen avalarse? Analizar notas protagonizadas por otro tipo de víctimas es de utilidad para responder esas preguntas. Esto es lo que vemos en el siguiente apartado.

\section{De cuando asesinar es el deber mayor para con la Patria}

El 15 de junio de 2015, el diario digital La Página difundió una nota titulada "Publican imágenes de pandilleros eliminados en San Pedro Perulapán". Lo primero que llama la atención 
es el verbo principal: "publican". Aunque omite el sujeto, la noticia en cuestión narraba que "una cuenta de Facebook" dio a conocer imágenes de seis pandilleros eliminados durante un operativo de la Policía y miembros de la Fuerza Armada, en un cantón del paracentral departamento de Cuscatlán. Luego agregaba que "el perfil suele publicar fotos de mareros (pandilleros) eliminados en enfrentamientos con las autoridades".

En efecto, en los últimos dos años, las nuevas tecnologías de la comunicación han facilitado el surgimiento de nuevos portales de información como parte del fortalecimiento de la esfera pública pero también del surgimiento de contraesferas (Lobo, 2017, p. 44). Específicamente, redes sociales como Twitter y Facebook son usadas para difundir material de interés para el generador del contenido. Por ejemplo, se han popularizado algunas cuentas anónimas como Héroe azul, que alude de forma directa al uniforme de los policías y que utiliza fuentes noticiosas vinculadas directamente a la PNC (Marroquín, 2016). Esta y otras páginas suelen publicar muchas fotos como las que La Página muestra en la nota en cuestión. Además, tienen particular interés en revelar la superioridad policial y, a su vez, mostrar la debilidad de las estructuras criminales, con la intención de incitar y promover el uso de la fuerza contra los pandilleros.

Entonces, el hecho de que el medio la tome como fuente, sumado a que no existe contraste periodístico ni una investigación reporteril que les permita cerciorarse de que, en efecto, los "eliminados" son pandilleros, valida y refuerza la intención de la fuente original: matar a los pandilleros está bien. El medio se convierte así en un replicador de la fuente interesada, probablemente con vínculos en la institución policial y, por ende, en el Gobierno, que busca legitimar unas muertes sí y otras no. Cabe recordar, que los medios copian el discurso oficial que establece que las pandillas son el enemigo a vencer y que, por lo tanto, quien luche contra ellas merece la aprobación de la población. De esta forma, los medios son cómplices en amplificar la amenaza pandillera (Wolf, 2012; Marroquín, 2007).

Pero luego está la palabra "eliminado". Esta, que figura en el titular pero también en el cuerpo de la nota, fue utilizada durante varios años por este medio digital para referirse al asesinato de pandilleros, exclusivamente. Así, los miembros de dichas estructuras no "mueren" ni "los matan"; son "eliminados". Aunque la Real Academia de la Lengua Española reconoce dicho verbo como sinónimo de matar, lo cierto es que el hecho de que sea designado solo para supuestos pandilleros y no para el resto de víctimas, connota mucho: a los miembros de maras se les elimina, se les desaparece. Tal como lo confirma otra acepción del diccionario: eliminar es "vencer al rival, impidiéndole con ello seguir participando en la competición". Entonces estos muertos están bien, pues le permiten a la Policía triunfar. De ningún modo consternan.

Algunas notas de El Blog podrían cumplir un papel de advertencia moralizante sobre lo que puede pasar a quien decide unirse o seguir dentro de las maras: el cementerio. Por ejemplo, este medio digital ${ }^{3}$, publicó el 16 de marzo de 2017 la noticia: "Así quedaron algunos de los pandilleros que murieron en San Martín tras enfrentarse a policías". Además de ese "asi" que refuerza la hipótesis de advertencia, el apoyo gráfico terminaba el sentido al titular. En

3 Uno de los cuatro más leídos en línea en el país, según la página de métricas alexa.com (diciembre 2017). 
este caso, se podían ver dos fotografías totalmente explícitas en las que los cuerpos de dos personas lucían tendidos, rodeados de sangre, poniendo en evidencia una violencia que no resulta para nada renacentista, ni cuidada, ni estética. El artículo narra que, en el municipio de San Martín, al oriente de la capital de San Salvador, nueve personas murieron producto de una balacera. De acuerdo a la nota, que cita solo la versión policial como fuente (de nuevo) se trataba de pandilleros que habían llegado a matar a tres mujeres "cuando se encontraron con una patrulla donde se conducían varios efectivos de la institución de seguridad pública". Producto de ese intercambio de disparos - prosigue la nota - fallecieron las seis personas, a los que identifica directamente como pandilleros.

Imagen 3 - Titular y una de las fotos publicadas en El Blog

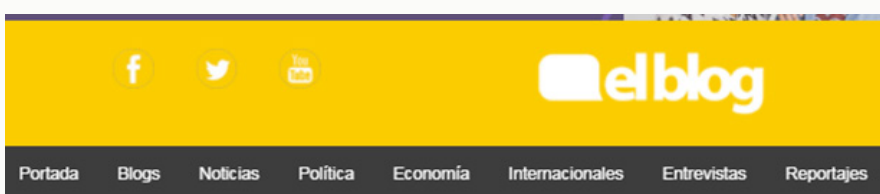

Fotos: Así quedaron algunos de los pandilleros que murieron en San Martín tras enfrentarse a policías

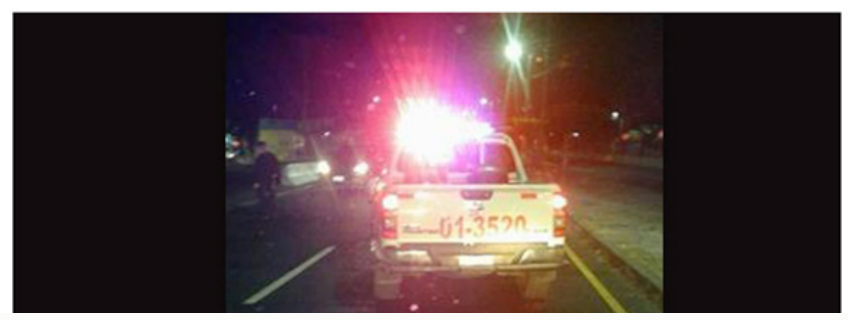

Fuente: Capturas de Pantalla tomada de El Blog: http://elbloq.com/noticias/reqistro-40521.html (20 de diciembre 2017)

Esta ligereza - llamarlos de una vez pandilleros - no es menor. Artículos de diarios digitales que por trayectoria o por posicionamiento de sus reporteros y editores han ganado prestigio y fama como medios creíbles y rigurosos, como El Faro y Factum, han revelado que existen estructuras dentro de la Policía dedicadas a la ubicación y asesinato extrajudicial de pandilleros (Avelar y Martínez, 2017; Valencia, Martínez y Valencia, 2015). En efecto, informes de la Procuraduría para la Defensa de los Derechos Humanos establecieron la existencia de este tipo de hechos. Además, al menos uno de los casos que involucran a policías en masacres de este tipo llegó a tribunales, donde el juez, aunque reconoció que hubo delito, dejó libres a los acusados debido a una acusación fiscal muy débil (Valencia, 2017).

Lo anterior tiene una importante implicación para el enfoque del presente artículo, pues significa que la fuente policial no siempre es definitiva ni totalmente confiable. Veámoslo con detenimiento: así como algunas estructuras internas de la corporación han hecho parecer que la muerte de algunos pandilleros ha sido producto de enfrentamientos en fuego cruzado cuando en realidad se ha tratado de ajusticiamientos, también puede ser peligroso dar por 
válida la versión de que toda foto de cadáveres publicada por algunos cuentas de Facebook en teoría vinculados a la institución policial y luego retomadas por los medios pertenecen efectivamente a personas que en vida fueron mareros. ¿Se le cree ciegamente a la Policía que los asesinados eran mareros? ¿Y aun si lo fueran, entonces estas no deben consternar? ¿Valen menos?

Es decir, estas notas que parecen validar algunas muertes podrían no siempre estar basadas en elementos definitivos. De esta forma, las víctimas que en el discurso periodístico sirven de escarmiento podrían haber sido personas que en vida, según la misma narrativa dicotómica de estos periódicos, podrían generar consternación si en su lugar hubieran sido "personas de bien". Eso no lo sabemos. La falta de rigurosidad periodística no permite saberlo. Pero más allá de si lo han sido o no, se puede inferir que en las noticias analizadas existen unas muertes que deben consternarnos y otras que, al contrario, debe servir como ejemplo, como escarmiento de aquellos que quieran seguir "el mal camino".

De hecho, ya no solo es el Gobierno y los medios quienes lo ven así. Ese discurso dicotómico respecto a los muertos de la violencia salvadoreña sigue su cadena hasta llegar a las audiencias. Estudios previos (Carballo, 2015; Marroquín, 2016), han revelado cómo los lectores de estos medios reproducen los mismos discursos de venganza e, incluso, satisfacción por algunas muertes, a la vez que reprochan el asesinato de la gente trabajadora a manos de pandilleros. Carballo (2015) encontró que el discurso más repetido entre los lectores de temas de violencia en medios como El Blog, La Página, La Prensa Gráfica y El Diario de Hoy (elsalvador. com) es que los pandilleros deben sufrir de la misma forma en los que ellos lo hacen con la población y con los policías; además de aprobar que las autoridades usen la fuerza, incluso fuera de la ley si es necesario, siempre y cuando sea contra los miembros de dichas bandas delincuenciales, asesinar es entonces un deber patrio. Los trabajos han determinado que las audiencias que opinan en muchos de los medios digitales y en sus redes sociales no suelen ser víctimas directas de pandillas, sino que se encuentran en ese otro círculo de la sociedad salvadoreña que ha interiorizado la inseguridad a través del consumo de medios. Dicho eso, es importante subrayar que estas audiencias salvadoreñas "ensayan nuevas formas de violencia. Ironizan, insultan, niegan, legitiman el uso de la fuerza, dividen el mundo en víctimas totales que deben ser protegidas y en victimarios terribles que deberán sufrir el peor de los castigos" (Marroquín, 2016, p. 234). Convocan entonces a una muerte que debe ser buscada, que es necesaria.

Estamos, pues, ante una narrativa periodística que cuenta muertes que consternan y otras que sirven de escarmiento. Desde un campesino asesinado cuando se dirigía a trabajar la tierra que no merecía morir hasta un grupo de pandilleros que "son eliminados" y que quedan "asi" (ensangrentados y tirados en la calle), como final a su vida errada luego de enfrentarse a tiros con la Policía, según una única fuente llamada también Policía. Un discurso que, a juzgar por esas otras investigaciones citadas, también ha hecho eco en las audiencias que las consumen. 


\section{De cómo nombrar algunas muertes de entre todas las muertes}

¿Quiénes mueren y quiénes son asesinados? ¿Cuál es el sentido de presentar de manera distinta una víctima en un país como El Salvador? Existe un mar de diferencia en la decisión periodística de utilizar un término o el otro. Ante alguien que ha fenecido debido a la acción de otro ser humano o grupo de humanos, la elección del periodista o del medio, entre plantearlo como alguien que ha muerto o que ha sido asesinado, no es menor. Se trata de una disyuntiva en el lenguaje que se suele repetirse en narrativas con claras dicotomías: buenos y malos, soldados contra guerrilleros, policías versus mareros, israelís contra palestinos (Pérez, 2015).

Parecería algo baladí, sin embargo, no lo es. Al decir que alguien resulta muerto, en el marco de un enfrentamiento, se omite al perpetrador, muere sin aparente responsable, muy probablemente porque se asume que es la suerte que corren o deben correr "los malos". No resulta igual decir que una persona ha muerto, a decir que ha sido asesinada, aunque el producto inmediato sea el mismo: un fallecido. El marco que se encierra detrás del término no es el mismo. No es igual saber que el abuelo murió, que darse cuenta que el abuelo fue asesinado. En ambos casos, el abuelo ha fenecido, pero las implicaciones sociales nunca son iguales.

Para Lakoff, las palabras, los términos que utilizamos implican y activan enmarcados o marcos referenciales que se manifiestan en nuestro comportamiento:

Los marcos son estructuras mentales que conforman nuestro modo de ver el mundo [...] En política nuestros marcos conforman nuestras políticas sociales y las instituciones que creamos para llevar a cabo dichas políticas. Cambiar nuestros marcos es cambiar todo esto. El cambio de marco es cambio social [...] Todas las palabras activan marcos conceptuales. Cuando se oye una palabra, se activa en el cerebro su marco (o colección de marcos). Cambiar de marco es cambiar el modo que tiene la gente de ver el mundo [...] Toda palabra, como elefante, evoca un marco, que puede ser una imagen o bien otro tipo de conocimiento: los elefantes son grandes, tienen unas orejas que cuelgan, y una trompa [...] La palabra se define en relación con ese marco (Lakoff, 2007, p. 17 y 23).

De la muestra de algunos medios en el año 2015, resulta interesante reconocer que, en su gran mayoría, los pandilleros resultaban "muertos" en el marco de los supuestos enfrentamientos con policías o con militares. Incluso tratándose de la misma historia y de la misma nota, como resultado del mismo enfrentamiento narrado, los policías o militares implicados no resultan "muertos", sino que ellos eran "asesinados" (Ver cuadro I). 
Cuadro I - Extractos de notas con términos muerte y asesinato

\begin{tabular}{|c|c|}
\hline Los que son asesinados & Los que se mueren \\
\hline $\begin{array}{l}\text { "Matan a otros dos policías en } 12 \text { horas. } \\
\text { Las pandillas recrudecen ola de asesinatos" } \\
\text { (EDH, } 16 \text { de enero de } 2015 \text {, Pág. } 2 \text {, de Jorge } \\
\text { Beltrán Luna). }\end{array}$ & $\begin{array}{l}\text { "Marero muere en tiroteo con policías en } \\
\text { Usulután" (EDH, } 22 \text { de diciembre, pág. 30, } \\
\text { Regina Miranda/David Marroquín) }\end{array}$ \\
\hline $\begin{array}{l}\text { "Pandilleros asesinan a un policía en un bar } \\
\text { de S. Miguel" (EDH, } 22 \text { de agosto, pág. 16, } \\
\text { Insy Mendoza). }\end{array}$ & $\begin{array}{l}\text { "Mueren tres mareros en tiroteos con PNC } \\
\text { y militares" (EDH, } 11 \text { de junio de 2015, pág. } \\
\text { 14, David Marroquín) }\end{array}$ \\
\hline $\begin{array}{l}\text { "Asesinan a un policía de la DAN cerca de } \\
\text { su vivienda" (EDH, } 23 \text { de agosto, pág. 12, D. } \\
\text { Escalante/J. Anaya/R. Zambrano). }\end{array}$ & $\begin{array}{l}\text { "Mueren dos delincuentes que se enfren- } \\
\text { taron con policías en Huizúcar" (EDH, } 31 \text { de } \\
\text { julio, pág. 42, Diana Escalante) }\end{array}$ \\
\hline $\begin{array}{l}\text { "En 2014-2015 se han asesinado la misma } \\
\text { cantidad de policías que en 2009-2013" (EF, } \\
4 \text { de Agosto, Nelson R. Z. /Daniel V. C.). }\end{array}$ & $\begin{array}{l}\text { "Dos pandilleros mueren al enfrentarse con } \\
\text { PNC" LPG, } 21 \text { de diciembre, pág. 10, Jessel } \\
\text { Santos/Francisco Alemán }\end{array}$ \\
\hline $\begin{array}{l}\text { "Matan a otro policía y a un custodio de } \\
\text { Quezaltepeque" (LPG, } 7 \text { de enero, Pág. 4, } \\
\text { Nelson Rauda Z./ Juan C. Barahona/Jessica } \\
\text { Ávalos). }\end{array}$ & $\begin{array}{l}\text { "También en San Juan Opico, en el cantón } \\
\text { Jabalinón, murió Emir M., un pandillero de } \\
16 \text { años, tras enfrentarse a miembros de la } \\
\text { Policía y de la Fuerza Armada (...) Otro pan- } \\
\text { dillero falleció en la colonia La Campan- } \\
\text { era, en Soyapango, San Salvador. Según } \\
\text { la Fiscalía General de la República (FGR), } \\
\text { esta muerte también fue en circunstancias } \\
\text { parecidas al (sic) de la víctima de San Juan } \\
\text { Opico" (LPG, } 7 \text { de enero, pág. 6, sin firma) }\end{array}$ \\
\hline $\begin{array}{l}\text { "Matan a un policía y a un agente del CAM } \\
\text { en S. S." (LPG, } 6 \text { de enero, Pág. 6, Nelson } \\
\text { Rauda/Javier Aparicio). }\end{array}$ & $\begin{array}{l}\text { "Mueren } 4 \text { personas en supuesto tiroteo } \\
\text { con PNC. La policía y la FGR aseguraron } \\
\text { que los muertos eran miembros de la pan- } \\
\text { dilla } 18 \text { que se enfrentaron agentes" (EDH, } \\
25 \text { de agosto, pág. } 20 \text {, sin firma) }\end{array}$ \\
\hline \multirow[t]{2}{*}{$\begin{array}{l}\text { "En menos de } 12 \text { horas, dos policías fueron } \\
\text { asesinados. Otro más fue atacado por su- } \\
\text { puestos pandilleros en San Martín" (LPG, } \\
16 \text { de enero, pág } 4 \text { / Suchit Chávez/Marcos } \\
\text { Salguero/Javier Aparicio). }\end{array}$} & $\begin{array}{l}\text { "Policías se enfrentan con mareros en cam- } \\
\text { pamento. Al ser sorprendidos, los delin- } \\
\text { cuentes se enfrentaron a balazos con las } \\
\text { autoridades y murieron dos delincuentes } \\
\text { (...) La policía informó que ambos pandil- } \\
\text { leros estaban involucrados en el asesinato } \\
\text { de un sargento del Ejército del Batallón } \\
\text { Presidencial" (EDH, } 26 \text { de agosto, pág. 21, } \\
\text { sin firma) }\end{array}$ \\
\hline & $\begin{array}{l}\text { "Incrementan homicidios en la zona ru- } \\
\text { ral del país (...) La Fiscalía informo que } 4 \\
\text { pandilleros murieron al enfrentarse con la } \\
\text { Policía (...) No menos de } 14 \text { personas fuer- } \\
\text { on asesinadas en las primeras } 10 \text { horas de } \\
\text { ayer en el país, la mayoría de víctimas eran } \\
\text { hombres que se dirigían a trabajar cuando } \\
\text { fueron atacados" (EDH, } 28 \text { de agosto, pág. } \\
36, \text { sin firma) }\end{array}$ \\
\hline
\end{tabular}




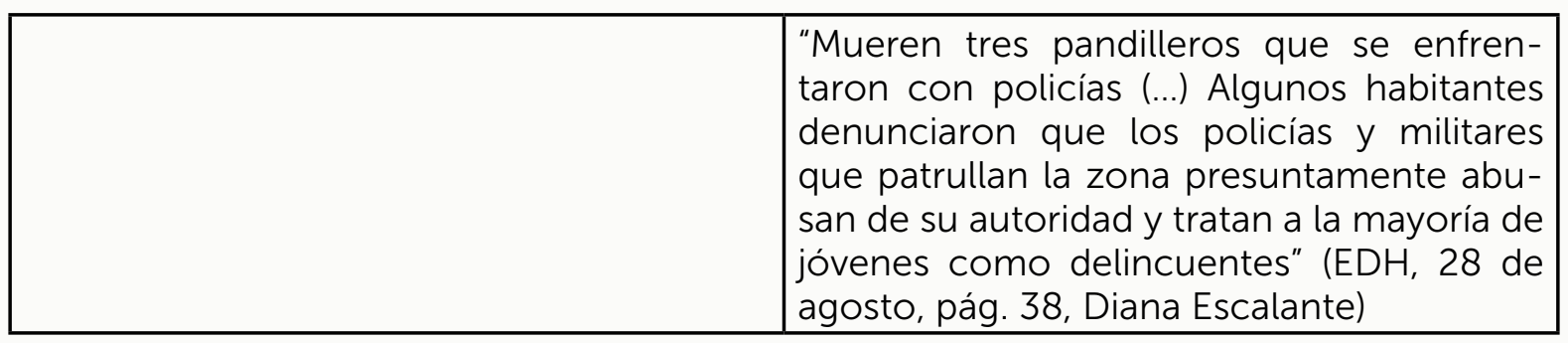

Fuente: Hernández-Anzora (2017) con información de LPG y EDH del año 2015

Esta narrativa dicotómica también es reconocible en algunas caricaturas, entrevistas o artículos de opinión de los periódicos. Por ejemplo, la caricatura de un miembro zombi de la PNC y el Ejército, infectado por un pandillero, en referencia a las infiltraciones de pandilleros en el Ejército y la PNC; u otra donde se presenta a la justicia favoreciendo a los pandilleros en detrimento de los elementos policiales.

La caricatura del miembro de la PNC-Zombi además refuerza visualmente la representación de las pandillas como una enfermedad, como una especie de cáncer social, tal como lo reconocía previamente Marroquín (2007). Siguiendo esa lógica narrativa, como todo cáncer, estas deben ser extirpadas, eliminadas. Y es precisamente allí donde se encuentran las claves de porqué unos son asesinados y otros solamente resultan muertos.

Esa clasificación entre unos que se mueren y otros que son asesinados, suele tomar mayor fuerza en relatos y contexto de guerra, y ciertamente el año 2015 fue narrado así en los medios escritos, aunque sin decirlo abiertamente, utilizando constantemente términos como: enfrentamientos, masacres, campamentos, bajas, emboscadas, etc. ${ }^{4}$

El año 2015 se contó como una suerte de guerra que fue subiendo de tono, un año en el que los malos (pandilleros) y los buenos (policías y militares) quedaron claramente dibujados, dejando poco espacio para los matices. Entonces, la suerte de los malos es morirse y la tragedia de los buenos es ser asesinados. ${ }^{5}$ Es decir, se parte de un marco prefijado o de una narrativa que deja poco espacio para comprender de manera más profunda el hecho narrado, pero también el fenómeno en general.

Desde otra perspectiva, esta narrativa maniquea asume y posiciona a unos como ciudadanos (los que son asesinados), mientras que los otros nunca lo han sido o dejaron de serlo en algún momento (los que se mueren). Es decir, se asume implícitamente que el Estado y sus garantías deben estar sólo para aquellos considerados como los buenos, rompiendo toda lógica y fundamento del Estado de derecho y los derechos humanos.

El gran problema con este tipo de narrativas periodísticas es que suelen terminar siendo utilizadas para justificar políticas de eliminación desde algunos voceros políticos e, incluso, desde las instituciones del Estado. Políticas que en definitiva sólo tienden a agravar la violencia

4 Solamente El Faro utilizó el término guerra para caracterizar el conflicto armado entre el Gobierno y las pandillas en el año 2015.

5 Fue hasta 2016 que comenzaron a publicarse algunas -aún escasas - primeras investigaciones periodísticas que mostraron otra cara sobre los supuestos enfrentamientos entre policías y pandilleros, no sin que los periodistas y medios responsables tuviesen respuestas no oficiales, directas e indirectas, lindantes con la intimidación y la amenaza por parte de algunas autoridades. 
asociada al fenómeno de las pandillas y que lejos de solucionar el problema, solamente lo magnifican y perpetuán.

Finalmente, la decisión periodística -consciente o no- para adjudicar muerte o asesinato a unos $\mathrm{u}$ otros respectivamente, no es una decisión de mera técnica o estilo, sino una cuestión de poder y de perspectiva ideológica, es decir, una decisión esencialmente política, que a la postre tiene sus respectivas consecuencias en la agenda pública y en la sociedad misma.

\section{La muerte transfigurada: las otras miradas a la República}

La sensibilidad de la artista no puede quedar sumida en el féretro que el destino le ha asignado, sino que debe trascenderlo, primero conceptualmente, en sus pensamientos y emociones, y luego en la aplicación de sus recursos creativos para liberarse de ese entorno que la asfixia, que la desgarra. La muerte es el sinsentido diario, la estupidez heredada, la degeneración social y cultural de un país cuya historia pareciera el eterno retorno de los criminales. Pero la muerte es también el gran misterio, la otra cara de una moneda cuya dimensión y nombre nunca conoceremos (Castellanos Moya, 2008)

En 2006, la artista plástica Mayra Barraza llevó a cabo su propio ejercicio de seguimiento de noticias e imágenes durante cien días. Para ello inauguró un blog al que tituló "Cien días en la república de la muerte". Cada día, sin saber qué iba a suceder, Mayra transcribió pacientemente las historias de muertos asesinados por la mano de otra persona y coleccionó las imágenes que ahí se mostraban.

Imagen 4 - Primera entrada al Blog "Cien días en la República de la muerte"

\section{0 días en la República de la Muerte}

Por Mayra Barraza

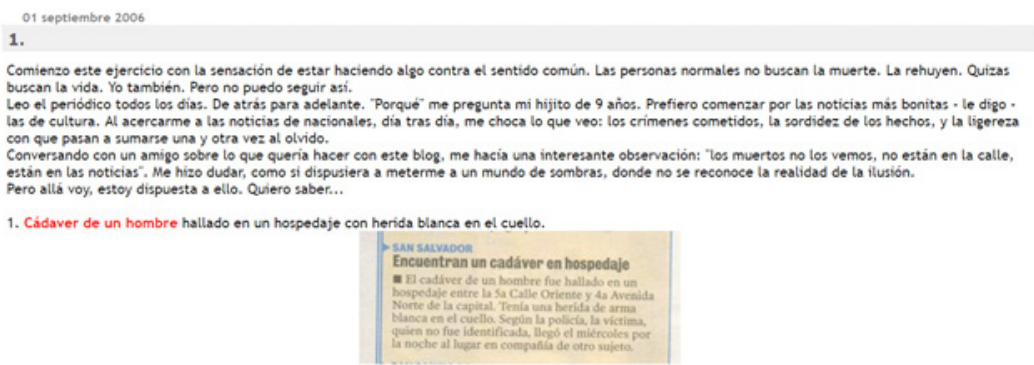

De 100 días

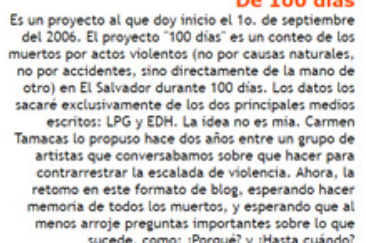

menos arroje preguntas importantes sobre lo que que

Días

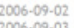

FUENTE: Barraza, Mayra (2006) República de la muerte. En: http://repblicadelamuerte.blogspot.com/. Recuperado el 28 de diciembre de 2017

Durante cien días, lo único que Mayra hace es contar, llevar cuenta de los muertos y contar(nos) historias. Transcribe con paciencia. Como bordando un texto incomprensible que de pronto adquiere el sentido monótono de la ritualidad. Doce años después, los sucesos que 
el discurso mediático cubre continúan la misma sucesión, el mismo tono de los hechos. Y es como una lluvia, monótona, que deslava la tierra y que cae sobre los vivos en el país de los muertos.

88.

Imagen 5 - Entrada del día 88. "Cien días en la República de la muerte"

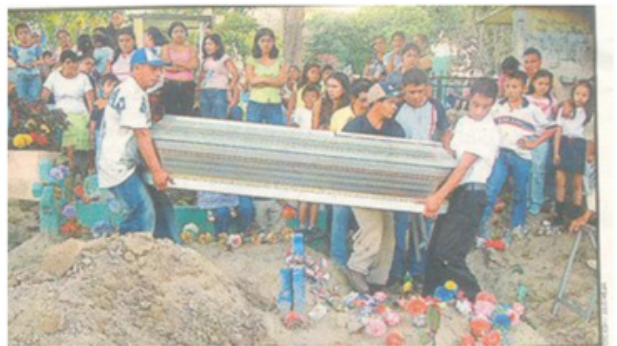

1. 'Tres jóvenes, quienes se encontraban departiendo en un restaurante... fueron acribillados a balazos por desconocidos. Dos de ellos murieron como consecuencias de lso múltiples impactos de bala que recibieron... Las victimas mortales son Gustavo Leonel Díaz Hernández, de 16 años; Francisco Javi Navarrete, de $14 \ldots$

2. "Un niño de 11 años fue asesinado ayer a balazos por varios sujetos... La victima fue identificada como José Roberto Trujillo Mejía. Conocidos del pequeño expresaron que el niño era estudiante de curto grado..." LPG dice: "el niño tenía cerca de 11 orificios de bala en la cabeza..."

FUENTE: Barraza, Mayra (2006). República de la muerte. En: http://repblicadelamuerte.blogspot.com/. Recuperado el 28 de diciembre de 2017

Esta revisión y una vivencia cotidiana de tres meses permiten posteriormente a la artista mostrar el rostro "transfigurado" de la muerte. Como muestra la Imagen 6, nos encontramos ante una propuesta que lo que hace es trascender lo evidente. Mucho menos directa, con múltiples posibilidades de interpretación, despojada del sentido moralista que los medios de comunicación presentan la muerte es entonces la muerte de todos los salvadoreños que habitan la República de la Muerte, con su propia bandera bordada en hilo rojo. Con los rastros entre la hierba de los desaparecidos, de los decapitados. Cuando el arte la toca, todas las muertes violentas son nuestras, y son un gesto de conmoción y de dolor.

Imagen 6 - Distintas obras de la serie República de la muerte
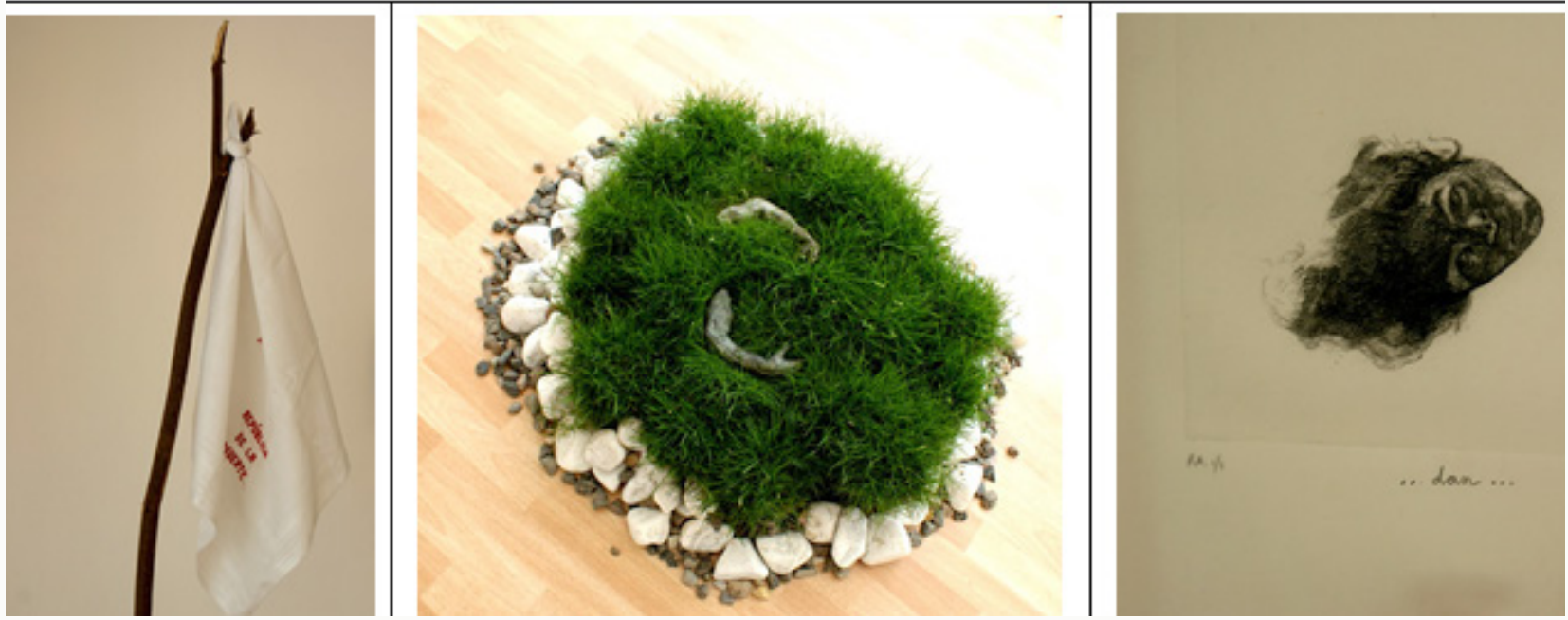

FUENTE: http://Fabricioestrada.blogspot.com/2010/06/republica-de-la-muerte-mayra-barraza-de.html, 30 de diciembre de 2017 
El escritor salvadoreño, Horacio Castellanos Moya, sostuvo al revisar la propuesta de Barraza que "Para la artista resulta difícil mantener la ecuanimidad con material de trabajo tan saturado de emociones extremas. Los motivos vienen de siempre y se repiten: el velorio y el entierro con los llantos desgarrados, el cadáver sin identificar y completamente despedazado, los rostros estupefactos por el sempiterno terror, las autoridades impotentes o cómplices, los familiares de la diáspora exigiendo justicia y ofreciendo apoyo y solidaridad. La tentación fácil para la artista ante esos motivos sería la denuncia, la indignación que cae en el kitsch, la inutilidad del panfleto. De esto parece consciente Mayra Barraza: intuye que su virtud radica en la singularidad de su mirada, en el pulso firme para recoger esas pasiones extremas y reinventarlas con el lenguaje del arte" (Castellanos Moya, 2008). Y esta es la mayor riqueza que nos presenta otro rostro de la muerte. La posibilidad de emanciparnos de los usos políticos y fáciles, para volver a lo esencial. La presencia omnipresente de la muerte en una sociedad habitada por múltiples violencias.

Diez años después de este trabajo, la misma Mayra Barraza se propone un nuevo reto, esta vez como curadora de una exposición que recoja una muestra representativa del arte de la postguerra, a 24 años del fin de un larguísimo conflicto armada que más bien parece prolongarse hasta la actualidad. La exposición titulada Horror vacui, con la curaduría de Mayra Barraza, los textos de Astrid Bahamond y la museografía de Carlos Díaz, propuso cuatro momentos, cuatro puntos cardinales, cuatro guías temáticas para recorrer la obra de siete grandes artistas salvadoreños que ha sido elaborada después de 1992, después de la guerra. El catálogo de la exposición con todas sus obras puede ser revisado acá:

De sangre y zozobra inauguró la exposición y enfatizó la afirmación que ya había elaborado Néstor García Canclini: el arte es el lugar de la inminencia (2011, p. 251), de lo que aún no era, pero quizás ya es. Mientras los periódicos internacionales mostraban que en $\mathrm{El}$ Salvador se había dado un acuerdo inédito, que la paz había llegado, que éramos ejemplo para el mundo; estos siete artistas, desde sus estudios, desde sus tribunas-lienzo no hicieron concesiones y volvieron a hablar de ese país que dio continuidad a la violencia: militarización de todo el territorio, país-sembrado-de-cuerpos, país de niños abandonados, de urbanizaciones aceleradas, de rostros que son máscaras, que son, como se nos muestra en la exposición, un corazón abierto y asombrado.

De sangre y zozobra mostró ese país no evidente, donde ritos ancestrales perviven entre los escombros de una nación que se creyó moderna. Un país que aún respira miedo y dibuja sus fronteras, desde esa herencia de los otros ismos que no provienen de la vanguardia, un país inventado a imagen y semejanza de sus propios machismos, de sus colonialismos, racismos, arrogancias, despotismos, suficiencias, fobias. La exposición colocó de nuevo el concepto de la muerte. Destacamos acá la obra del artista Luis Lazo y su Corazón de piñata (Imagen 7). Una piñata con rostro vacío y con expresión horrorizada, una piñata que evoca sangre y que está hecha para un ritual violento de la niñez: para ser golpeada, despedazada y repartida. A través de esta obra, Lazo muestra una metáfora fundamental de la muerte en El Salvador, es esa golpeada, despedazada, repartida, horrorizada y sangrienta. 


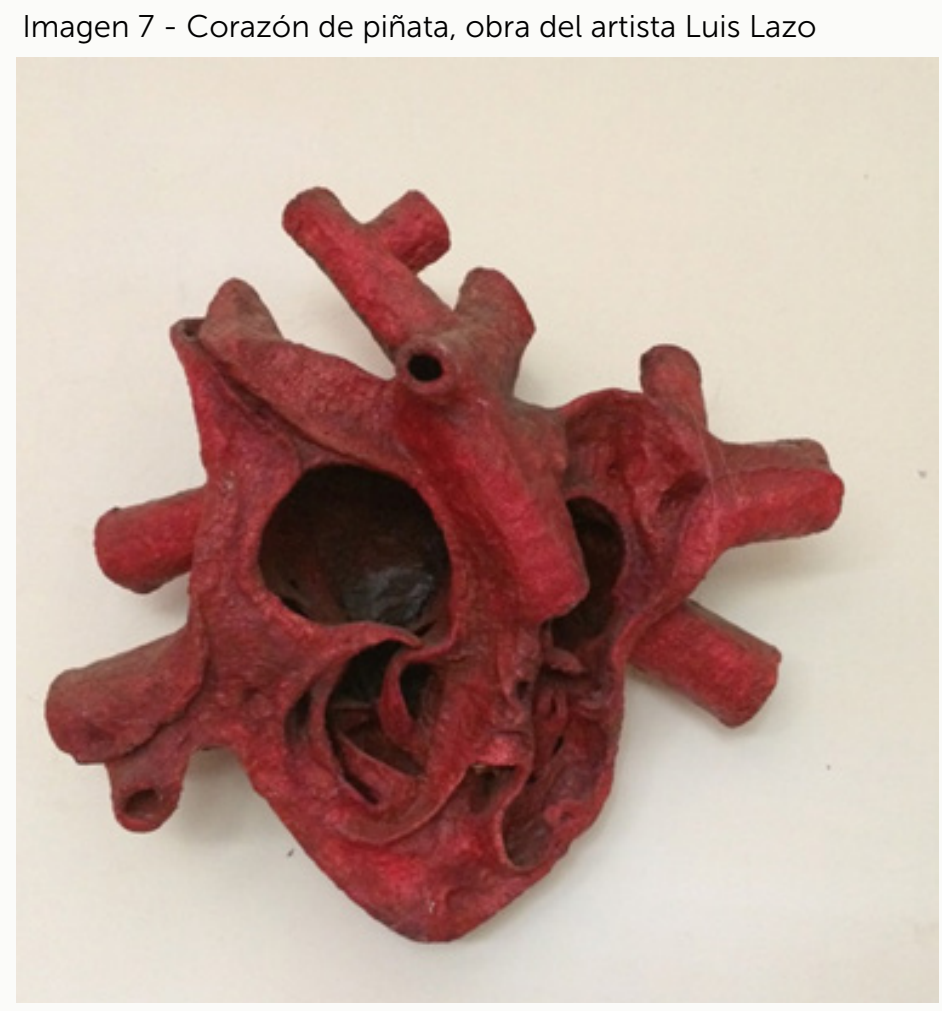

FUENTE: Secretaría de cultura de la presidencia. (2016) Horror Vacui. Arte de Postguerra. San Salvador: Sala Nacional de Exposiciones.

\section{Brevísimo epílogo}

Por lo que no debe morir, tu pueblo: canto.

Otto René Castillo. Vámonos patria a caminar (2017[1965])

Muchos análisis se han hecho para revisar los usos políticos de la muerte. Desde la década de 1960, en la República de El Salvador, la muerte fue una herramienta de represión política. La muerte con tortura, con saña, con ventaja. Una mano blanca pintada en la puerta de la casa era la señal para un opositor político que los grupos paramilitares le daban unas horas para huir, antes de ser asesinado. De ese uso se transitó a otro con la llegada de los acuerdos de paz en 1992. Había que buscar un culpable de las muchas violencias y las pandillas se fueron construyendo en el discurso público como el mejor chivo expiatorio. Pero para ello, tenían que ser fortalecidas, tenían que mostrar su crueldad frente a la sociedad. Para ello, era necesario, que los espectadores se enfrentaran de manera directa y sin filtros a las muertes más cruentas. Acá no había que disimular quiénes eran los asesinos, porque ellos merecerían después su propia muerte. Aunque los integrantes de las pandillas son originarios de los sectores populares, el discurso de las instituciones gubernamentales, magnificado por los medios, los separa del pueblo salvadoreño, ese que no debe morir.

Durante un largo tiempo, en El Salvador, los distintos regímenes políticos de derecha y de izquierda han fortalecido el poder de las pandillas y han creado ideológicamente a la pandilla 
como el gran enemigo del estado. Esto es lo que nos muestran los medios. Pero también nos ocultan que hay beneficios para los poderosos en esa manera de construir socialmente una realidad determinada. La mano dura, la súper mano dura, la tregua, la suspensión de las garantías constitucionales, la salida del ejército a las calles ha conseguido réditos para las clases dirigentes. La violencia es también un negocio 6 y para mantenerlo, las representaciones de la muerte deben seguir ciertos patrones. Es el arte, como señalamos al inicio, uno de los pocos discursos que rompe con las fórmulas oficiales para proponer otras posibilidades: el extrañamiento, la crítica, la mirada que, quizá, podría llevarnos a entender que los otros, también son parte de nosotros en el país de todas las muertes.

\section{Referencias Bibliográficas}

AVELAR, Bryan y MARTÍNEZ, Juan José. En la intimidad del escuadrón de la muerte de la policía. Revista Factum. On-line, 22/ago/2017. Disponible en: <http://revistafactum.com/en-laintimidad-del-escuadron-de-la-muerte-de-la-policia/s. Acceso en: 20/12/2017.

BERGMAN, Adrian. Sin razón aparente: conflictos sociales y violencia en la postguerra. En: BERGMAN, Adrian y MELÉNDEZ, Oscar (Comp.). Violencia en tiempos de paz: conflictividad y criminalización en El Salvador. San Salvador: Dirección de Investigaciones. Secretaría de Cultura, p. 221-252, 2015.

CARBALLO, Willian. "Like" a la violencia selectiva: Análisis del discurso sobre pandillas a través de los comentarios de lectores en el Facebook de periódicos digitales salvadoreños. Abierta Anuario de Investigación. Santa Tecla, El Salvador, n. 9, p. 16-28, 2015. Disponible en: < https:// issuu.com/ecmh/docs/abierta2017_n9>. Acceso en: 20/12/2017.

CASTELLANOS MOYA, Horacio. La apuesta de Mayra. El ojo de Adrián - Arte, literatura, Centroamérica. On-line, 2008. Disponible en <http://elojodeadrian.blogspot.com/2008/09/ terraemotus-mayra-barraza.html>. Acceso en: 20/12/2017.

CASTILLO, René. Vámonos patria a caminar. Guatemala: F y G Editores, 2017[1965]. 224p.

FLORES ARGUETA, Dulcinea. Periodismo judicial y cobertura de violencia en El Salvador. San Salvador: Universidad Centroamericana José Simeón Cañas, 2014. 20p. Disponible en: <http:// www.uca.edu.sv/letras/wp-content/uploads/2016/02/Resumen-ejecutivo-PeriodismoJudicialUCA.pdf>. Acceso en: 20/12/2017.

GARCÍA CANCLINI, Néstor. La sociedad sin relato. Antropología y estética de la inminencia. Buenos Aires: Katz, 2011. 264p.

HERNÁNDEZ-ANZORA, Marlon. Narrativas sobre las maras en la prensa escrita salvadoreña en el año 2015. Tesis (Maestría en Comunicación). Universidad Centroamericana José Simeón Cañas, Antiguo Cuscatlán, El Salvador, 2017. 74p.

6 PROGRAMA DE NACIONES UNIDAS PARA EL DESARROLLO. ¿Cuánto cuesta la violencia a El Salvador?. San Salvador: PNUD 2005. 
JUARROZ, Roberto. Séptima poesia vertical. Buenos Aires: Monte Ávila editores, 1982.

LAKOFF, George. No pienses en un elefante: lenguaje y debate político. Foro Complutense, Universidad Complutense de Madrid, 2007. 176p.

LOBO, Sascha. Cómo influyen las redes sociales en las elecciones. Nueva Sociedad. Buenos Aires, n. 269, p. 40-44, maio/jun. 2017. Disponible en: < http://nuso.org/media/articles/ downloads/1.TC_Lobo_269.pdf>. Acceso en: 20/12/2017.

MARROQUÍN, Amparo. Indiferencias y espantos. Relatos de los jóvenes de pandillas en la prensa escrita de Centroamérica. En REY, Germán. Los relatos periodísticos del crimen. Bogotá: Centro de Competencia en Comunicación, p. 55-91, 2007.

MARROQUÍN, Amparo. El espejo del miedo: Audiencias salvadoreñas y notas de inseguridad en redes sociales. En: FOCÁS, Brenda y RINCÓN, Omar (Eds.). Inseguridad, medios y miedos: una mirada desde las experiencias y las prácticas cotidianas en América Latina. Cali: Universidad Icesi, Facultad de Derecho y Ciencias Sociales, p. 215-240, 2016. Disponible en: < http://repository. icesi.edu.co/biblioteca_digital/bitstream/10906/81177/7/focas_inseguridad_medios_2016.pdf>. Acceso en: 20/12/2017.

MARTEL, Roxana. Las maras: nuevas formas de espanto y control social. . En: VALENZUELA ARCE, José Manuel; NATERAS DOMINGUEZ, Alfredo y REGUILLO CRUZ, Rossana (Eds). Las maras: identidades juveniles al límite. México: Universidad Autónoma Metropolitana, p. 83-125, 2007.

MOODIE, Ellen. Las secuelas de la paz. Criminalidad, incertidumbre y transición de la democracia en El Salvador. San Salvador: UCA Editores, 2017. 410p.

PÉREZ, Isabel. Morir o ser asesinado: el choque de dos narrativas en Israel y Palestina. Eldiario. es. On-line, 10/nov/2015. Disponible en: <http://www.eldiario.es/desalambre/Morir-asesinadoIsrael-Palestina-narrativas_0_450755473.html>. Acceso en: 20/12/2017.

VALENCIA, Roberto. El juicio bufo de San Blas. El Faro. San Salvador, 22/sept/2017. Disponible en: <https://elfaro.net/es/201709/salanegra/20868/El-juicio-bufo-de-San-Blas.htm>. Acceso en: $20 / 12 / 17$.

VALENCIA, Roberto; MARTÍNEZ, Oscar y VALENCIA, Daniel. La policía masacró en la Finca San Blas. El Faro. San Salvador, 22/jul/2015. Disponible en: <https://salanegra.elfaro.net/es/201507/ cronicas/17205/La-Polic\%C3\%ADa-masacr\%C3\%B3-en-la-finca-San-Blas.htm>. Acceso en: 20/12/17.

VASILACHIS, Irene. Representations of young people associated with crime in El Salvador's written press. Critical Discourse Studies. S/l, v. 4, n. 1, p. 1-28, 2007.

VÁSQUEZ, Olga y MARROQUÍN, Amparo. Entre gritos y silencios. La narrativa de la prensa salvadoreña sobre la tregua entre pandillas. Nueva Sociedad. Buenos Aires, n. 249, ene/feb 2014. Disponible en: <http://nuso.org/media/articles/downloads/4005_1.pdf>. Acceso en: 20/12/17.

VERÓN, Eliseo. Lenguaje y comunicación social. Buenos Aires: Nueva Visión, 1971. 230p.

WOLF, Sonja. Creating Folk Devils: Street Gang Representations in El Salvador's Print Media. Journal of Human Security. On-line, v. 8, n. 2, p. 36-63, 2012. 
En el país de todas las muertes. El Salvador, políticas de seguridad y representaciones de los asesinatos

Recebido em: 16 de janeiro de 2018

Aprovado em: 13 de junho de 2018 